\title{
MANAGEMENT CONTROL TRADITIONAL PERSPECTIVES VERSUS EMERGING PERSPECTIVES: A LITERATURE REVIEW
}

\author{
Gaetano della Corte, University of Rome, Sapienza, Department of Law and Economics of Productive \\ Activities, Rome, Italy \\ Federica Ricci, University of Rome, Sapienza, Department of Law and Economics of Productive Activities, \\ Rome, Italy \\ Salvatore Ferri, University of Naples "Parthenope", Department of Business and Economics Studies, Naples, \\ Italy
}

dx.doi.org/10.18374/IJBR-19-3.4

\begin{abstract}
Scope The aim of this paper is to examine the previous studies conducted on the Management Control Systems (MCS) through a systematic literature review in order to highlight the emerging paradigm. Methodology In an attempt to outline the role and the functions of the Management Control System, this paper reviews the most important issues in the literature on MCS and offers a framework that allows understanding the various forms of MCS that have occurred over the course of the years, from the first works to the current MCS issues. In particular, this paper examines and reviews different perspectives of MCS. The main purpose of the framework is to capture the major MCS areas with the consideration of internal and external, social, economic and cultural aspects of an organizations' activities. Studies of the functions of management control systems have shifted from focusing simply on economic transactions within an organization to more subjective constructs. This has paved the way for the emergence of new ideas that emphasize the importance of socio-cultural factors alongside economic approaches within an organization in the field of MCS, such as political and cultural aspects. Findings/Implications The main purpose of this review is to understand and analyze the prevailing concepts and types of MCS and to identify new emerging knowledge that incorporates the economic aspects of the organization's activities with social settings. Furthermore, the paper, through a structured literature review, aims to provide a more complete analysis of the role and functions of the management control system in modern competitive contexts, trying to fill up the gap between the various studies on the subject from the earlier research works.
\end{abstract}

Keywords: management control systems, MCS, framework, performance measurement, management accounting 